\title{
Credit risk assessment: Evidence from banking industry
}

\author{
Hassan Ghodrati and Gholamhassan Taghizad"
}

Department of Management and Accounting, Kashan Branch, Islamic Azad University, Kashan, Iran

\section{H R O N I C L E A B S T R A C T}

Article history:

Received January 20, 2014

Accepted 5 July 2014

Available online

July 72014

Keywords:

Credit Risk

Artificial Neural Network

Default Risk

Macroeconomic Variables

Iranian banks

\begin{abstract}
Measuring different risk factors such as credit risk in banking industry has been an interesting area of studies. The artificial neural network is a nonparametric method developed to succeed for measuring credit risk and this method is applied to measure the credit risk. This research's neural network follows back propagation paradigm, which enables it to use historical data for predicting future values with very good out of sample fitting. Macroeconomic variables including GDP, exchange rate, inflation rate, stock price index, and M2 are used to forecast credit risk for two Iranian banks; namely Saderat and Sarmayeh over the period 2007-2011. Research data are being tested for $\mathrm{ADF}$ and Causality Granger tests before entering the ANN to achieve the best lag structure for the research model. MSE and R values for the developed ANN in this research respectively are $86 \times 10^{-4}$ and 0.9885 , respectively. The results showed that ANN was able to predict banks' credit risk with low error. Sensibility analyses which has accomplished on this research's ANN corroborates that M2 has the highest effect on the ANN's credit risk and should be considered as an additional leading indicator by Iran's banking authorities. These matters confirm validation of macroeconomic notions in Iran's credit systematic risk.
\end{abstract}

\section{Introduction}

The globalization of financial markets along with remarkable growth on knowledge has created complexity in banking activities. In the past, banks' main operations are normally limited in receiving deposits and granting facilities for gaining interests (Kiss, 2003; Gan \& Lee, 2005). Banks' competition development is on decreasing the borders of their traditional activities interests. The emergence of new financial markets and omission of traditional borders between banks and nonbanking institutions along with financial crisis happened occasionally in international level, have drawn financial authorities and bankers' attention to themselves. Banks are in the exposure of various types of risks based on their own activities. The risk of banking activities is generally divided into the two parts of intra organizational and extra organizational ones. In banking industry, economic activity risk includes credit, liquidity, commercial, financial risk, income and prices structural risk, and the risks caused by banking debts and assets structure. These kinds of risks can be omitted via right

*Corresponding author.

E-mail addresses: gt_a23@yahoo.com (G. Taghizad) 
management. Extra organizational risks are not caused by banks' economic activities, but by lateral economic and political conditions. Legal and political risks are the main extra-organizational risks.

Credit risk is the outcome of fiscal transaction between benefit (money) users and providers and is defined as a means of transactions. Therefore, possibility of predicting and identifying this type of risk has been interesting for credit and financial institutions. Although banks are facing with many risks but credit-risk has the main role on their profitability potential according to their activity sort. In this study, different variables such as gross domestic production growth, inflation rate, stock prices, and conversion rates are used for predicting default rate, as the country banking main hazards.

Hashemi Nodehi (1998) dealt with the factors causing referred charges (claims) and facilities expired overdue over the period 1986-1997 in bank Maskan. They reported that executive system expansion of this bank was not suitable with its network increment, so the referred charges percentage and facilities expired overdue were added to the whole charges during the examined period. Furthermore, inflation and the difference between facilities interest rate and market interest rate caused delay in clients' payment. Najafi (2000) reviewed bank's procedures for collecting banking delayed receivables and reviewed the procedures for following and collecting the bank delayed receivables, legally. He implied that liability facilities had more delayed rate compared with other facilities. Habibi (2002) studied the influential factors on paying back agricultural facilities in due time over the period 1984- 2000. She indicated that economic indexes such as inflation had a direct influence on the amount of bank's banking delayed receivables. Mansoori (2002) compared three groups of Melat Bank clients, using two models of Classic (regression) and artificial intelligence (neural network) to measure the risk rate and credit capacity. He reported that the neural network model was more efficient than the linear regression model in measuring clients' credit capacity; but it was not so efficient comparing to logistic regression model.

Ruintan (2005) measured the credit risk among corporate clients of Keshavarzi Bank using the logic regression method. She found that among the financial rates, cash and current rates had the most important part in dividing the clients based on the credit risk, and the logit regression was very efficient in evaluating the credit risk of clients. Sabzevari and Noorbakhsh (2006) evaluated the corporate clients of Karafarin Bank, using the logistic scoring model and non-parametric method of CART. The resulted indicated that both models had almost the same predicting accuracy for all cases, but for small cases, CART was more accurate. Tehrani and Fallah Shams (2006) designed and examined the efficiency of credit risk model using the linear probability, logistic and artificial neural networks models. The findings indicated that the relation between the variables in credit risk predicting model had not been linear and the most efficiency was associated with the artificial neural networks and logistic models, respectively. Isazade and Mansoori (2008) used the neural network model to estimate credit risk and capacity of Tejarat Bank. They suggested that the neural network model was more efficient than the traditional models in predicting the credit risk of clients.

Mehrara et al. (2010) attempted to design a model for credit risk and rating departments of Parsian Bank, using logit regression method, probit model and neural network model GMDH. The findings implied that the type of collateral and the debt ratio had the greatest effect on the default probability variable. Rahmani and Esmaili (2010) compared the artificial neural network model, logistic regression, and differential analysis to predict the default risk. They suggested that neural network was more efficient than logistic regression and differential analysis in prediction. In addition to the variable considered above, the credit policy and collecting policies could influence on the default rate in leasing companies.

Vaez et al. (2010) studied the impact of business cycles on default rate of bank loan and services and determining facilities optimized package. They suggested that macroeconomic variables had a significance impact on credit risk of banking network in Iran. Khoshsima et al. (2011) studied the relationship between efficiency and risk in Iranian banking system and indicated that parametric method is relatively superior to nonparametric method in banks assessment and ranking. They also 
suggested that SFA method (parametric) was better than MEA method (nonparametric). Moreover, there was a significant relationship between credit risk, liquidity operation and efficiency in Iranian banking system.

Khodai Vale Zaqerd and Qalami Bavil (2012) studied the factors influencing on the default rate of banking receivables. They suggested that management efficiency, leveraged ratio, reducing the financial costs, increased assets risk, assets logarithm, and the ratio of loans to deposits had an impact on the probability of banking receivables default. Ebrahimi and Daryabar (2012) studied the factors influencing on the credit risk, risk prediction, credit ranking of bank clients using data envelopment analysis method, logistic regression, and neural network. The results showed that neural network model was more efficient in predicting credit risk of real clients and credit rating. Iran Supreme Banking Institute (2012) compared the efficiency of credit risk in linear probability, logistic and artificial neural networks models to predict credit risk of bank clients. The results showed that artificial neural network and logistic models had better prediction accuracy, respectively.

Mansoori and Azar (2012) assessed the credit risk of bank clients using multilayer perceptron neural networks. They showed that neural networks and logistic regression had the same potentiality, but neural network models were more potential in estimating the credit capacity of clients. Mori (1909) formulated measuring and calibrating credit risk of bonds, for the first time. Beaver (1966) presented the multivariate logistic regression model to determine companies' bankruptcy. Altman (1968) presented a model to measure credit risk of companies' bonds as a multivariate scoring model which is named as $\mathrm{Z}$ score. Altman used differential analysis for the first time and attempted to distinguish the bankrupt and non-bankrupt companies using the financial ratio values. Keeton and \& Morris (1987) conducted a research on 2400 commercial banks over the period 1979-1985. The results indicated that economic conditions was the main variable influencing on having non-current facilities in other banks.

Rambaldi et al. (1992) conducted a research to validate agricultural co-operatives. The results showed that the higher amount of liquidity in a co-operative, the higher rate of net income to average for cooperative assets, higher sale output, and the lower productive diversity are among the most important factors affecting on accepting the credit banking receivables. Jenson (1992) used the neural network model to score the credit of 618 loan applicants. The results assessed network at the accuracy of 1113\%. Allen and Sanderz (1995) applied Altman's model to forecast credit risk of borrowers and concluded that the model is so powerful in predicting credit risk. Disai et al. (1996) investigated the ability of neural networks and traditional statistical techniques such as linear audit analysis and linear regression analysis to make credit scoring models.

Feldman (1997) suggested that using credit assessment models on the ability of small firms would effect on repayment risk and costs reduction. Desai et al. (1997) compared linear differential analysis neural network to logistic regression. They suggested that neural network works better than linear differential analysis and had a relatively similar performance compared with logistic regression, considering the classification of loan applicants of good and bad credit. Almer and Profski (1998) applied perceptron multi-layer neural network model with Altman variables. The results indicated that perceptron model had a more productive power than credit scoring models. West (2000) examined the quantitative models in credit weakness. The results indicated that applying neural networks was capable of improving scoring accuracy.

Boussabaine and Wanoous (2000) preferred fuzzy - neural methods to traditional methods in predicting the bankruptcy. They believed that fuzzy- neural methods could be more efficient in evaluating business risks and improving decisions for investors, shareholders, managers and other decision makers. Malhotra and Malhotra (2002) compared the efficiency of fuzzy- neural reasoning systems compatible with multiple discerning analysis and their results indicated the superiority of this method with alternative ones. Koopman and Lucas (2003) showed that credit risk moves almost along and at the same direction with macroeconomic variables; and this is an important point in risk 
management process. Behr and Güttler (2004) studied 40154 small and medium companies over the period 1998-2001. The results indicated that the positive growth rate of the assets, the higher rate of depreciation value to selling value, higher liquidity, and higher sales value were factors influencing on firms' ability to repay received facilities. Jimns and Sorina (2005) showed that the rate of noncurrent facilities is in direct correlation with the increase in the loan portfolio and economic growth. Moreover, collateral requirements are not taken so seriously during the boom. Pesola (2005) examined the effect of macroeconomic variables on banking system in Belgium, Germany, Greece, Spain, and UK making use of an econometric model and recommended that loan losses were due to negative macroeconomic shocks.

Lismo Bonchai et al. (2005) studied agricultural loans in Thailand using logistic model and two social neural network model (PNN) and multi-layer feedback neural network (MLFN). They showed that the prediction accuracy of PNN was more than two other models. Bennell et al. (2006) applied neural network to assess the credit based on data from credit agencies and various countries and concluded that artificial neural network was more efficient than others. Pesaran et al. (2006) studied the effects of macroeconomic variables on credits losses and reported that macroeconomic variables could influence on banking credit risk. Chen et al. (2006) tested Merton, Brakeman and Tarter, Black Cox, Jacky (for 2 periods) Long Staff - Schwartz and non- parametric models. They indicated that distribution features of stock outputs and internal compensatory rate were the most important factors and random interest rate had a lower effect.

Dovern et al. (2010) used vector autocorrelation model to assess macroeconomic factors on credit risk of bank clients in Germany. The research indicated that there was a direct correlation between the non-current facilities and GDP, retail price index and interest rate. Goukasian and Seaman (2009) studied 250000 tenancy contracts comparing logistic regression method, differential analysis, and neural network. They concluded that differential analysis could predict more accurate than logistic regression and neural network. Espinoza and Prasad (2010) studied the factors influencing on noncommercial facilities in Persian Gulf banks using econometric method. They found that the proportion of non-commercial facilities, capital value, and the amount of commercial interest have an indirect correlation with economic growth.

\section{The proposed study}

Since the research is conducted according to descriptive inference method, the research aims to answer the following questions:

Main Question: How accurate is the neural network in predicting credit risk of bank clients in the realm of this research?

1) What are the effective factors for predicting bank clients' credit risk?

2) What are the outcomes of using neural system for predicting bank clients' credit risk?

3) How precise is the neural system in predicting bank clients' credit risk?

This study is functional in terms of the objective because of using available methods and models in evaluating bank clients' credit risk. Regarding avoidance of random sampling during providing data and neural system method, descriptive method was used for concluding data analysis. Research plan is post event because of using functional historical data. Research statistical society was monthly periods (intervals) over the period 2007-2011 on two Iranian banks named Sarmayeh and Saderat.

The neural system used in this research is a kind of post-release one that its simulation algorithm is indicated in Fig. 1. The network has three hidden layers with 8, 8 and 1 neuron, respectively. Transitive functions used in the network were expressed. Fig. 2 demonstrates the summary of the neural network model. 


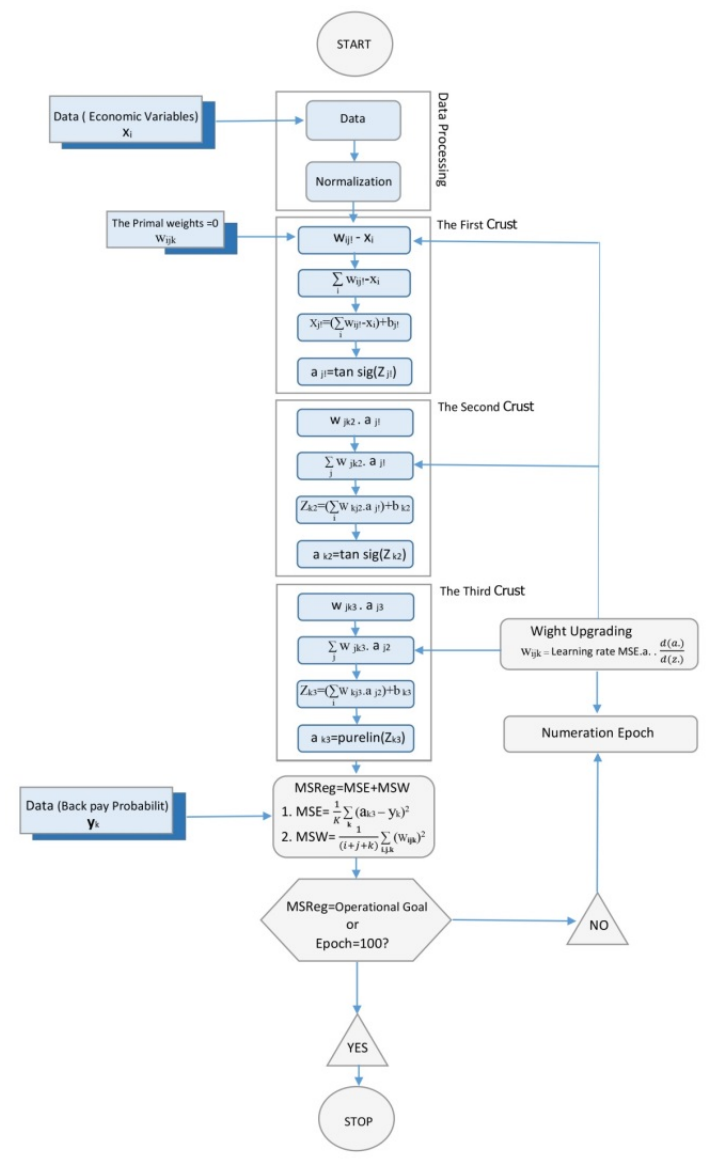

Fig. 1. The proposed structure of neural network

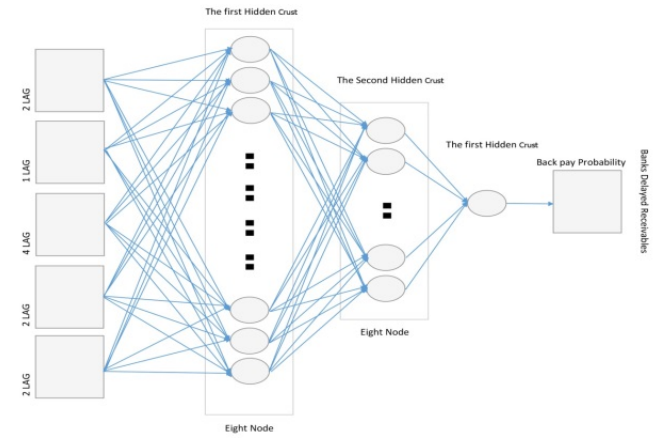

\section{Research findings}

Describing the data, evaluation premises are explored, and then the analysis of banks credit risks findings are examined through the research context. In this section, descriptive statistics of each variable are offered. The study uses six variables including Currency conversion, Gross domestic product (GDP), Liquidity, Stock price index, inflation rate and banks delayed receivables growth rate. A.D.F test is used to examine data similarity in the first stage of data analysis and its results shown in Table 1.

\section{Table 1}

Stability Test Results

\begin{tabular}{lcc}
\hline Variable & Statistic & Sig. Level \\
\hline Delayed Receivables & -3.512153 & 0.0009 \\
Exchange Rate & -7.657826 & 0.0000 \\
GDP & -20.30812 & 0.0001 \\
Inflation Rate & -2.999539 & 0.0409 \\
Stock Price Index & -6.752980 & 0.0000 \\
M2 & -7.346427 & 0.0000 \\
\hline
\end{tabular}

According to similarity significant level that equals zero, data series were accepted. Grainger causality test performed for variables and optimized arrearage summarized in Table 2. 
Table 2

The Optimum Lags

\begin{tabular}{lccccc}
\hline Variable & GDP & Inflation & M2 & Stock Price index & Exchange rate \\
Lag & 1 & 2 & 4 & 3 & 1 \\
\hline
\end{tabular}

Simulation was performed based on the algorithm and network bias was started from 0. Having performed inputs into the network; the network was taught with L.M Trine algorithm. Fig. 3 shows error correction process by teaching network:

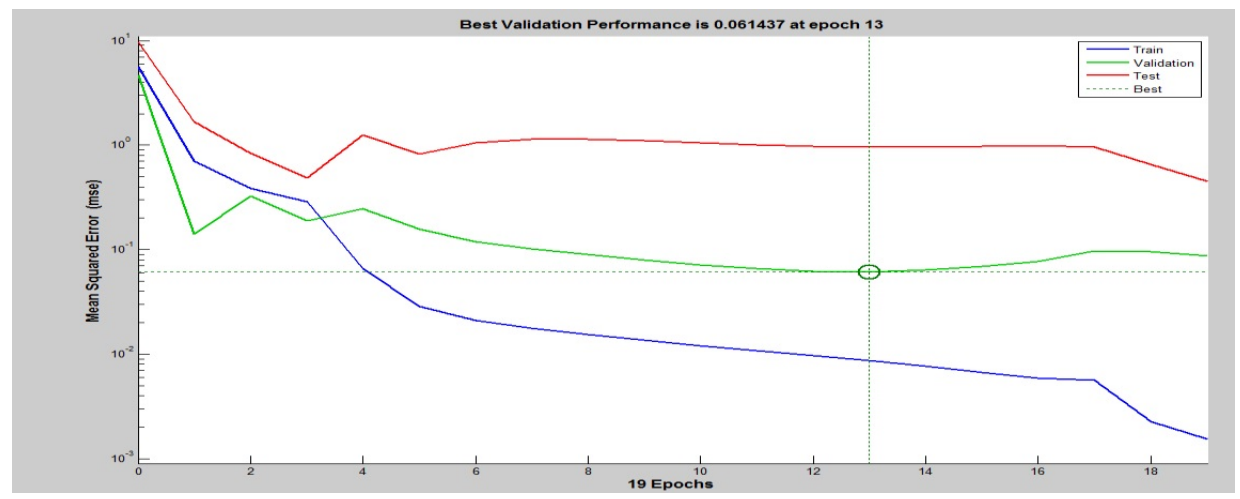

Fig. 3. Simulation Errors Trend

Network error ratio declined to less than 5-10 in 19 epoch $\mathrm{m}$. The average of network error square reached to $86 \times 10^{-4}$ in general and after measuring credit and testing by data from the out of educational area. Measuring credit showed results conformity prediction on real data accuracy coefficient 0.98850 . The values of $\mu \pm \sigma$ were used for each of the variables in this section that are explained respectively. Table 2 shows the results of the sensitivity analysis.

Table 2

The summary of sensitivity analysis

\begin{tabular}{lcccc}
\hline & \multicolumn{2}{c}{$\mu+\sigma$} & \multicolumn{2}{c}{$\mu-\sigma$} \\
\cline { 2 - 5 } Variable & Changes & Absolute Changes & Changes & Absolute Changes \\
\hline Delayed Receivables & 0.02858 & 0.028584 & -0.02858 & 0.028584 \\
Exchange Rate & -0.045672 & 0.045672 & 0.02567 & 0.025667 \\
GDP & 0.082865 & 0.082865 & -0.10105 & 0.101052 \\
Inflation Rate & 0.30643 & 0.306427 & -0.23985 & 0.23985 \\
\hline Stock Price Index & -0.02103 & 0.02103 & 0.047025 & 0.047025 \\
\hline
\end{tabular}

\section{Discussion and conclusion}

The results showed that ANN was able to predict banks' credit risk with low error. Sensibility analyses which has accomplished on this research's ANN has corroborated that M2 had the highest effect on the ANN's credit risk and should be considered as an additional leading indicator by Iran's banking authorities. These matters have also confirmed validation of macroeconomic notions in Iran's credit systematic risk. Comparing this research's results with a completely similar research on Iranian banking network, shows constancy between our research and the on which developed about Iranian banks (Ebrahimi \& Daryabar, 2012; Tehrani \& Fallah, 2005; Khodai Vale Zaqerd \& Qalami Bavil, 2012). 


\section{References}

Anderson, R., \& Sundaresan, S. (2000). A comparative study of structural models of corporate bond yields: An exploratory investigation. Journal of Banking \& Finance, 24(1), 255-269.

Allen, J. C. (1995). A promise of approvals in minutes, not hours. American Banker, 28.

Altman, E. I. (1968). Financial ratios, discriminant analysis and the prediction of corporate bankruptcy. The Journal of Finance, 23(4), 589-609.

Beaver, W. H. (1966). Financial ratios as predictors of failure. Journal of Accounting Research, 5, 71-111.

Behr, P., \& Güttler, A. (2007). Credit risk assessment and relationship lending: An empirical analysis of German small and medium-sized enterprises. Journal of Small Business Management, 45(2), 194-213.

Bennell, J. A., Crabbe, D., Thomas, S., \& Gwilym, O. A. (2006). Modelling sovereign credit ratings: Neural networks versus ordered probit. Expert Systems with Applications, 30(3), 415425.

Berge, T. O., \& Boye, K. G. (2007). An analysis of banks' problem loans. Economic Bulletin (Norges Bank), 78(2), 65-76.

Boussabaine, A. H., \& Wanoous, M. (2000). A Neurons fuzzy Model for Predicting Business Bankruptcy. In Business Applications of Neural Networks: The State-of-the-Art of Real-World Applications (ed.), 55-69.

Chen, R., Hu, S., \& Pan, G. (2006) Default Prediction of Various Structural Models. Rutgers University, National Taiwan University, and National Ping-Tung University of Sciences and Technologies.

Collin-Dufresne, P., \& Goldstein, R. S. (2001). Do credit spreads reflect stationary leverage ratios?. The Journal of Finance, 56(5), 1929-1957.

Desai, V. S., Conway, D. G., Crook, J. N., \& Overstreet, G. A. (1997). Credit-scoring models in the credit-union environment using neural networks and genetic algorithms. IMA Journal of Management Mathematics, 8(4), 323-346.

Desai, V. S., Conway, D. G., Crook, J. N., \& Overstreet, G. A. (1997). Credit-scoring models in the credit-union environment using neural networks and genetic algorithms. IMA Journal of Management Mathematics, 8(4), 323-346.

Dovern, J., Meier, C. P., \& Vilsmeier, J. (2010). How resilient is the German banking system to macroeconomic shocks?. Journal of Banking \& Finance,34(8), 1839-1848.

Ebrahimi, M., \& Daryabar, A. (2012). Credit risk management in bank system- data envelopment analysis approach and logistic and neural system. Invest Knowledge Periodical, 1(2).

Espinoza, R. A., \& Prasad, A. (2010). Nonperforming loans in the GCC banking system and their macroeconomic effects. International Monetary Fund.

Feldman, R. (1997). Small business loans, small banks and big change in technology called credit scoring. The Region, (Sep), 19-25.

Gan, C., \& Lee, M. (2005). An analysis of credit scoring for agricultural loans in Thailand. American Journal of Applied Sciences, 2(8), 1198.

Goldstein, M., \& Turner, P. (1998). Banking crises in emerging economies: origins and policy options. Available at SSRN 52074.

Goukasian, L., \& Seaman, S. (2009). Strategies for predicting equipment lease default. Journal of Equipment Lease Financing, 27(1), 1-7.

Habibi, S. (2002). Examining effective factors on bank loan on-time repayment on bank Keshavarzi (agriculture bank). Tehran University, Economic Department, Un-Published Dissertation

Hashemi Nodehi, M.M. (1998). Evaluating causes of past nuisance and banking delayed receivables Bank facilities in bank Maskan, during 65-76. Tehran University, Management Department, Un-Published Dissertation 
Iran Supreme Banking Institute/ Islamic republic of Iran central bank (2012). Designing and explaining credit risk model in country banking system. $16^{\text {th }}$ Islamic banking system association.

Isazade, S., \& Mansoori Gargary, H. (2009). Credit risk and capacity estimation of Tejarat bank clients via neural network. Basirat periodicals, 42.

Jensen, H. L. (1992). Using neural networks for credit scoring. Managerial Finance, 18(6), 15-26.

Jesus, S., \& Gabriel, J. (2006). Credit cycles, credit risk, and prudential regulation.

Keeton, W. R., \& Morris, C. S. (1987). Why do banks 7 loan losses differ?. Economic Review, 321.

Khodai Vale Zaqerd, M., \& Qalami Bavil, S. (2012). Evaluating effective key factors on declination risk of accepted banks in Tehran stockbrokerage market. Stock Brokerage Periodical, 21.

Khoshsima, R., \& Soheili Tash, M. (2011). Credit risk, operational risk and liquidity effects on Iran banking system efficiency. Investigatory-scientific periodicals of budget and planning, 4 .

Kiss, F. (2003). Credit scoring processes from a knowledge management perspective. Social and Management Sciences, 11(1), 95-110.

Koopman, S. J., \& Lucas, A. (2005). Business and default cycles for credit risk. Journal of Applied Econometrics, 20(2), 311-323.

Malhotra, R., \& Malhotra, D. K. (2002). Differentiating between good credits and bad credits using neuro-fuzzy systems. European Journal of Operational Research, 136(1), 190-211.

Mansoori, A., \& Azar, A. (2012). Designing and explaining efficient model of bank facilities allocation, neural systems approaches, linear logistic regression. Modarres scientificinvestigatory, 26.

Mansoori, A. (2003). Designing and explaining mathematical model of bank loan allocation, neural network and classical models approach. Tarbiat Modarres University, Un-Published Dissertation.

Mehrara, M. et al. (2009). Credit ranking of Parsian bank legal clients. Periodicals of Economic Modeling, 3.

Mueller, C. (2000). A simple multi-factor model of corporate bond prices. Available at SSRN 248369.

Najafi, A. (2000). Criticism and exploration of bank's banking delayed receivables collecting methods from a legal view. University of Tehran, Law Department, Un-Published Dissertation.

Pesaran, M. H., Schuermann, T., Treutler, B. J., \& Weiner, S. M. (2006). Macroeconomic dynamics and credit risk: a global perspective. Journal of Money, Credit and Banking, 12111261.

Pesola, J. (2005). Banking fragility and distress: An econometric study of macroeconomic determinants. Bank of Finland Research Discussion Paper, (13).

Rahmani, A., \& Esmaili, Q. (2009). Neural network efficiency, distinction analysis and logistic regression in predicting declination, Accounting Economy Periodicals, 7(4).

Rambaldi, A. N., Zapata, H. O., \& Christy, R. D. (1992). Selecting the best prediction model: An application to agricultural cooperatives. Southern Journal of Agricultural Economics, 24, 163163.

Sabzevari, H., \& Noorbakhsh, I. (2006). Contrustive analysis of logistic parametric credit preferring model via non-parametric method CART. $17^{\text {th }}$ Islamic banking association, Iranian supreme banking Institution.

Tehrani, M., \& Fallah, S. (2005). Designing and explaining credit risk model in country banking system. Social and human sciences magazine of Shiraz university, 2(43), 45-46

Vaez, M., Amiri, H., \& Haydari, M. (2010). Analyzing commercial cycles effects on Iran banking declination rate and indicating facilities optimized package for total banking system. $21^{\text {st }}$ annual conference of currency and fiscal policies, monetary and economic periodicals, 3(7).

West, D. (2000). Neural network credit scoring models. Computers \& Operations Research, 27(11), 1131-1152. 